\title{
PEMANFAATAN AKUN YOUTUBE BERKONTEN PEMBELAJARAN BAHASA MANDARIN DALAM LITERASI DIGITAL PADA ERA PANDEMI
}

\author{
Wafda Nabila Haqqie ${ }^{1}$, Primardiana Hermilia Wijayati ${ }^{2}$, dan Aiga Ventivani. ${ }^{3}$ \\ Universitas Negeri Malang \\ E-mail: * primardiana.hermilia.fs@um.ac.id
}

ABSTRAK

ABSTRACT
Artikel ini merupakan hasil penelitian tentang pemanfaatan akun YouTube berkonten pembelajaran bahasa Mandarin dalam literasi digital siswa kelas X. Pada era pandemi ini, pembelajaran daring menjadi pilihan utama, demikian juga dalam pembelajaran bahasa Mandarin di SMA dan membuat literasi digital tetap sangat diandalkan. Tujuan dari penelitian ini adalah mendeskripsikan pemanfaatan akun YouTube berkonten pembelajaran bahasa Mandarin dalam literasi digital siswa kelas X SMA. Data penelitian ini dikumpulkan melalui kuisioner dengan responden sebanyak 25 siswa yang dilakukan secara daring dan dianalisis menggunakan metode kuantitatif deskriptif

Hasil dari penelitian menunjukkan bahwa akun YouTube berkonten pembelajaran bahasa Mandarin secara keseluruhan dapat membantu proses literasi digital siswa kelas $\mathrm{X}$ dalam pembelajaran bahasa Mandarin, temuan penelitian membuktikan bahwa siswa dapat menguasai enam elemen literasi digital meliputi: a) information literacy, b) digital scholarship, c) ICT literacy, d) career and identity management, e) communication and collaboration dan f) media literacy. Data penelitian menunjukan bahwa hasil siswa meningkat. Adapun elemen literasi digital yang belum sepenuhnya atau masih rendah dikuasai siswa adalah learning skills.

Kata Kunci: Literasi Digital , Pemanfaatan , Era Pandemi , Siswa, YouTube berkonten bahasa Mandarin

This article is the result of research on the use of YouTube accounts with Chinese learning content in digital literacy for first grade high school students. In this pandemic era, online learning is the main choice, as well as learning Mandarin in high school and making digital literacy very reliable.

The purpose of this study is to describe the use of YouTube accounts with Chinese learning content in digital literacy for first grade high school students. This research data was collected through questionnaires with 25 students as respondents, which was conducted online and analyzed using descriptive quantitative methods

The results of the study show that YouTube accounts with Chinese learning content as a whole can help the digital literacy process of first grade high school students in learning Mandarin, the research findings prove that students can master six elements of digital literacy including: a) information literacy, b) digital scholarship, c ) ICT literacy, d) career and identity management, e) communication and collaboration and f) media literacy. The research data shows that student outcomes have 
increased. The elements of digital literacy that have not been fully or still poorly mastered by students are learning skills.

Keywords: Digital Literacy, Utilization, Pandemic Era, Students, YouTube with Chinese content

PENDAHULUAN Saat ini pembelajaran daring menjadi pilihan utama, tidak terkecuali pembelajaran bahasa Mandarin pada jenjang SMA. Dunia pendidikan pada Era Revolusi Industri 4.0 juga menitikberatkan pola pada digitalisasi, terutama literasi digital (Schwab, 2016). Istilah literasi digital juga pertama kali diperkenalkan pada 1990-an dan digambarkan sebagai kemampuan untuk memahami dan menggunakan informasi dalam berbagai format dari berbagai sumber ketika itu disajikan melalui komputer (Reyna et al., 2018).

Literasi digital adalah kemampuan menggunakan teknologi dan informasi dari piranti digital secara efektif dan efisien dalam berbagai konteks seperti akademik, karir dan kehidupan sehari-hari (Riel \& Christian, 2016). Literasi digital juga bisa dilakukan jika memanfaatkan peran media teknologi. Adanya peran teknologi internet, seperti media sosial dan platform digital dan memanfaatkan peran teknologi tersebut sebagai sumber informasi mengenai pengetahuan dan pendidikanmerupakan salah satu inovasi dalam literasi digital. Hal tersebut sesuai dengan yang dibutuhkan oleh situasi pandemi ini dan konsep dari revolusi industri 4.0, yaitu dapat membentuk generasi kreatif, inovatif, serta kompetitif.

Ada tujuh elemen literasi digital (Littlejohn, 2009), tujuh elemen literasi digital tersebut meliputi: information literacy, digital scholarship, learning skills, ICT literacy, career and identity management, communication and collaboration, dan media literacy. Tujuh elemen tersebut sangat penting dikuasai dalam proses literasi digital. Selain itu, dalam menguasai elemen tersebut siswa juga memerlukan kompetensi lain yang mendukung media digital.

Penggunaan media juga memiliki peranan penting untuk siswa dalam memelajari bahasa seperti bahasa Mandarin, seperti yang dikemukakan oleh Kharis et al., (2020) bahwa penggunaan media memainkan peran penting dalam proses pembelajaran, dan itu dapat lebih menjelaskan apa yang tidak dapat dijelaskan oleh komunikasi verbal. Hal tersebut menjadi bagian dari revolusi pembelajaran yang perlu disadari oleh para pendidik. Artinya, para guru pun perlu belajar bahwa perubahan sedang berlangsung dan percepatan pembelajaran harus dilakukan dengan menggunakan media yang sesuai dengan Revolusi Industri 4.0 yaitu media digital seperti YouTube.

YouTube telah menjadi salah satu media sosial paling populer di dunia, lebih dari satu miliar pengguna dengan lebih dari 6 miliar jam waktu menonton setiap bulan (Lam \& Woo, 2020). Hasil penelitian juga menunjukkan bahwa video YouTube tampil lebih baik dalam menargetkan pemirsa yang berusia 45 tahun pada tahun ketiga dan memiliki peningkatan signifikan dalam persentase pemirsa yang berada dalam usia yang ditargetkan pada 45 tahun atau lebih tua $(62,0 \%$ vs $46,0 \%$, df $=2$, chi $=147,46, p<0,01)$. Salah satu tujuan utama YouTube adalah konten video yang bersifat edukasi, mengingat setiap hari lebih dari 1 miliar video terkait proses pembelajaran ditonton di 
YouTube (YouTube Creator Academy, 2018). YouTube saat ini menjadi salah satu tujuan utama masyarakat terutama kalangan siswa untuk mencari beragam konten dalam bentuk video, termasuk konten pembelajaran bahasa Mandarin. Beberapa akun YouTube yang memuat konten pembelajaran bahasa Mandarin adalah Nihao Indonesia, Little Fox Chinese, Tjen Wandra.

Dari sekian banyaknya akun YouTube berkonten pendidikan bahasa Mandarin, peneliti memilih akun YouTube "Little Fox Chinese", karena akun YouTube tersebut memiliki konten yang beragam, tidak hanya pembelajaran bahasa Mandarin, namun cerita, kebudayaan dan lain sebagainya yang berhubungan dengan negara Tiongkok. Dalam media akun YouTube "Little Fox Chinese" terdapat animasi video menarik disertai tulisan hanzi dan pinyin. Pihak dari akun YouTube "Little Fox Chinese" juga setiap minggu secara konsisten membagikan dua video pembelajaran bahasa Mandarin.

Hasil penelitian yang dilakukan Setyaningsih et al., (2019) tentang model penguatan literasi digital melalui pemanfaatan Elearning menunjukkan bahwa ada peningkatan kemampuan literasi digital yang digunakan. Hal tersebut terbukti melalui pemanfaatan $e-$ learning elemen communication and collaboration literasi digital.

METODE

Penelitian ini menggunakan metode deskriptif kuantitatif untuk mengetahui pemanfaatan akun YouTube berkonten pendidikan bahasa Mandarin dalam literasi digital siswa di era pandemi ini. Instrumen yang digunakan adalah kuesioner. Responden dari penelitian ini merupakan siswa kelas X MIA atau Matematika dan Ilmu Alam 2 yang berjumlah 25 siswa. Responden menerima kuesioner yang berperan sebagai informasi dalam mengetahui proses literasi digital siswa kelas X Matematika dan Ilmu Alam 2 atau biasa disingkat menjadi X MIA 2 pada matapelajaran bahasa Mandarin melalui pemanfaatan akun YouTube berkonten pendidikan bahasa Mandarin seperti "Little Fox Chinese” di SMAK Santa Maria Malang.

Tahap pengumpulan data dilakukan secara daring memanfaatkan aplikasi whatsapp dan google form, dimulai dengan menyiapkan instrument, memdistribusikannya dan mengumpulkannya Kembali. melalui aplikasi whatsapp. Sebelum memanfaatkan akun YouTube siswa terlebih dahulu mendengarkan penjelasan guru tentang materi perkenalan diri, kemudian para siswa membuat percakapan terkait perkenalan diri dengan teman sekelasnya melalui fitur voice note whatsapp. Pada pertemuan selanjutnya, peneliti menjelaskan kembali materi perkenalan diri dalam bahasa Mandarin, kemudian peneliti mengirimkan link salah satu video dari akun YouTube "Little Fox Chinese” tentang perkenalan diri (我叫敏宇 wǒ jiào min yǔ), siswa memanfaatkan akun YouTube tersebut dalam pembelajaran bahasa Mandarin. Siswa melakukan aktivitas menjabarkan, menarik kesimpulan video, memberikan ide-ide terkait video yang telah ditampilkan dalam bentuk lisan dan siswa kembali membuat percakapan terkait perkenalan diri dengan teman sekelasnya melalui fitur voice note whatsapp. Hasil dari kegiatan tersebut dipantau dengan cara siswa mengisi pertanyaan-pertanyaan melalui aplikasi google form tentang elemen literasi digital.

Data dari google form dianalisis menggunakan metode 
kuantitatif deskriptif yaitu, menghitung persentase di tiap poin berdasarkan indikator yang telah dibagi dalam kisi-kisi lembar kuesioner angket, selanjunya mendeskripsikan data dan menyimpulkan hasil sesuai dengan teori. Data disajikan dalam bentuk diagram.

\section{PEMBAHASAN Hasil}

Berikut disajikan hasil literasi digital yang mencakup literasi digital, elemen information literacy, digital scholarship, learning skills, ICT literacy, career and identity management, communication and collaboration, dan media literacy.

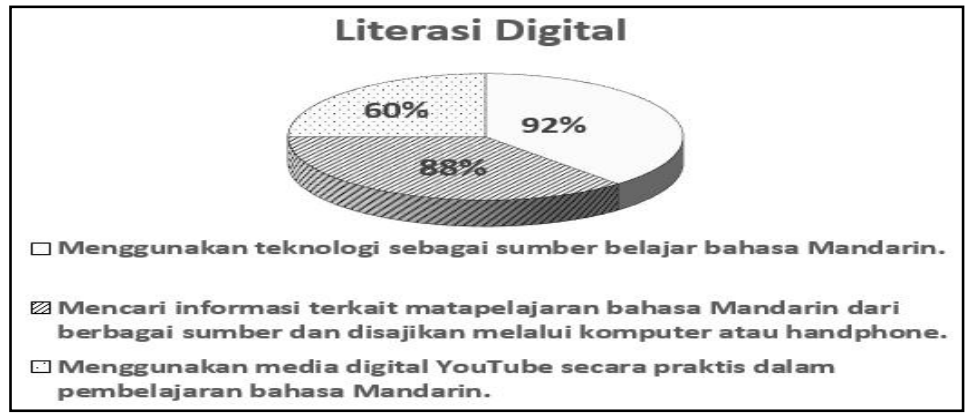

Diagram 1 : Literasi Digital

Pada diagram diatas hanya $60 \%$ siswa berpendapat bahwa media youtube praktis, dan ada $40 \%$ yg menyatakan tidak praktis, karena media YouTube menggunakan internet dan sebagian besar siswa tidak memiliki dana yang memadai untuk membeli kuota. Selanjutnya peneliti menjabarkan persentase setiap elemen literasi digital.

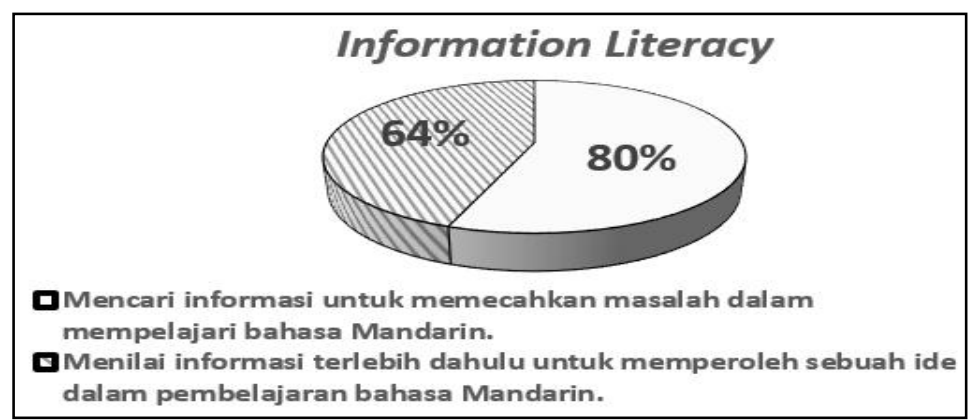

Diagram 2 : Information Literacy

Pada diagram elemen information literacy sebesar $64 \%$ berpendapat siswa menilai terlebih dahulu informasi dari YouTube, karena mereka menghindari informasi yang salah (hoax) dari YouTube. Selanjutnya hasil elemen literasi digital kedua yaitu digital scholarship.

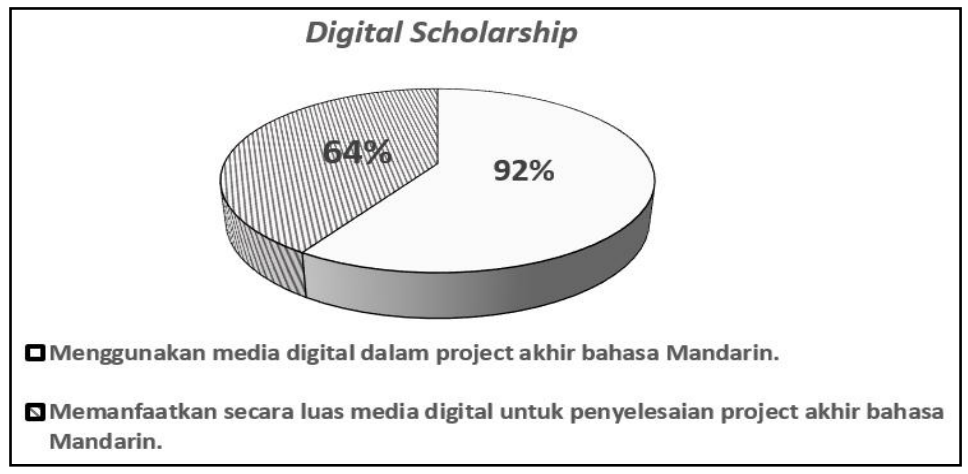




\section{Diagram 3 : Digital Scholarship}

Hasil diagram elemen digital scholarship menunjukkan 64\% memanfaatkan secara luas media digital dalam menyelesaikan project akhir, dan ada $36 \%$ siswa belum secara luas memanfaatkan media digital, mereka masih tetap memanfaatkan media konfensional dalam menyelesaikan project akhir. Selanjutnya peneliti menjabarkan elemen literasi digital learning skills.

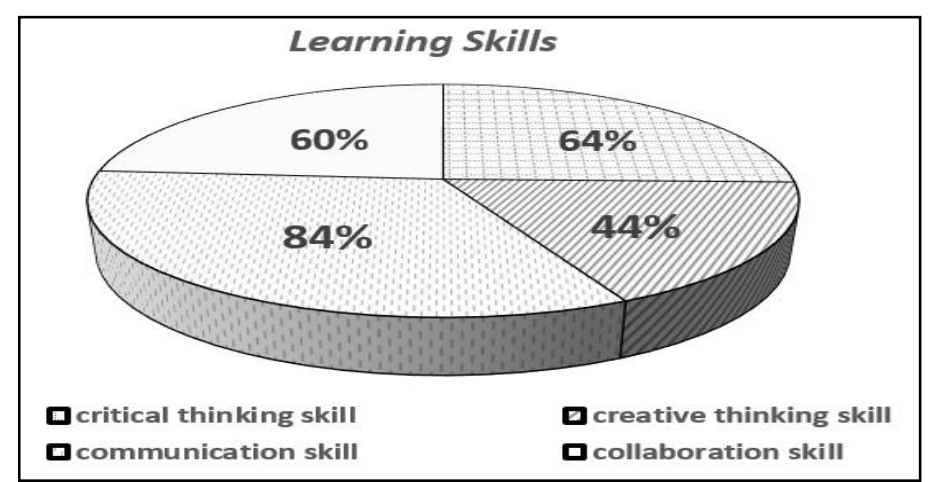

Diagram 4 : Learning Skills

Dari hasil diagaram diatas (elemen learning skill) menunjukkan bahwa sebesar $44 \%$ siswa mampu dalam hal creative thingking skill, namun 56\% belum mampu, seperti memberikan ide-ide baru setelah menonton video YouTube, karena siswa hanya menikmati menonton video. Selanjutnya hasil elemen literasi digital kedua yaitu ICT literacy.

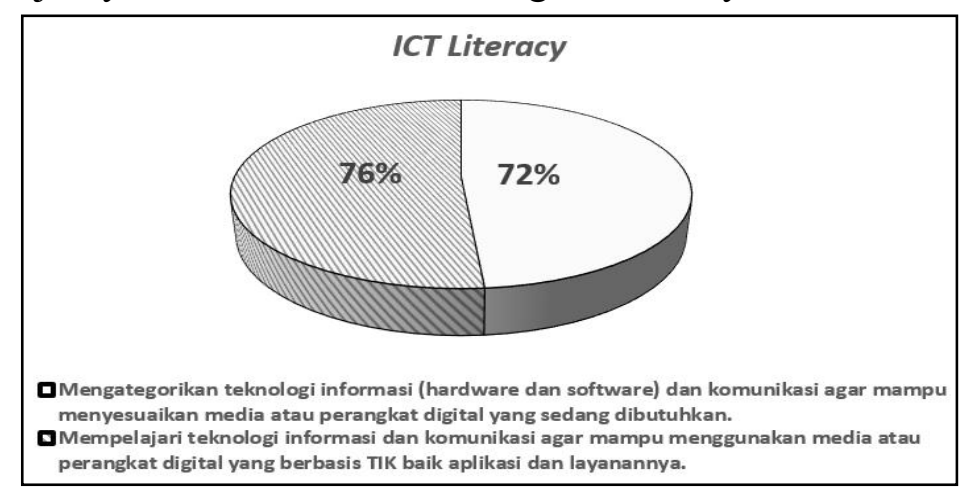

Diagram 5 : ICT Literacy

Hasil elemen ICT literacy ada 76\% siswa mempelajari teknologi informasi dan komunikasi agar mampu menggunakan media atau perangkat digital yang berbasis TIK baik aplikasi dan layanannya, karena situasi pandemi yang mengharuskan siswa melakukan pembelajaran jarak jauh. ICT literacy menjadi keterampilan dasar dalam pembelajaran jarak jauh. Selanjutnya peneliti menjabarkan hasil data pada variabel tujuh elemen literasi digital dengan elemen career and identity management.

Pada elemen career and identity management, maksud dari career and identity management yaitu, mengelola diri sendiri yang berkaitan dengan mengatur waktu belajar secara online. Hasil data dari elemen career and identity management dapat diketahui bahwa sebanyak $20 \%$ responden belum mampu mengelola diri sendiri yang berkaitan dengan mengatur waktu belajar secara online, namun ada $80 \%$ 
responden mampu mengelola waktu belajar secara online. Sebagian besar responden $(80 \%)$ selama melaksanakan pembelajaran daring tidak ada kesulitan dalam mengatur waktu belajar karena semua serba online seperti materi pembelajaran, pengumpulan tugas dan lain sebagainya. Selanjutnya dijabarkan hasil dari variabel tujuh elemen literasi digital elemen communication and collaboration.

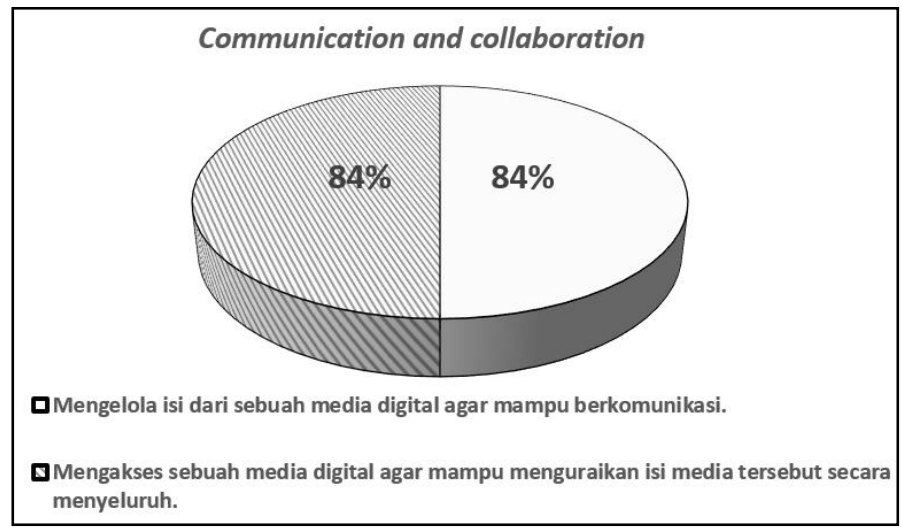

Diagram 6: Communication and Collaboration

Pada diagram diatas hanya $84 \%$ siswa berpendapat bahwa dapat mengelola media digital agar mampu berkomunikasi dalam pembelajaran daring dan ada $16 \%$ yg menyatakan tidak untuk berkomunikasi, karena beberapa siswa mengelola media digital untuk bermain handphone daripada mengikuti proses pembelajaran bahasa Mandarin. Selanjutnya peneliti menjabarkan persentase media literacy.

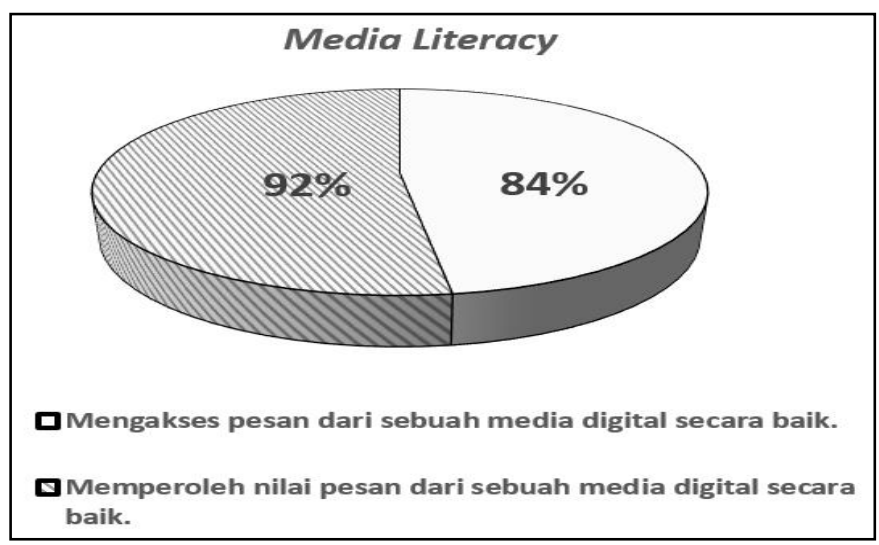

Diagram 7 : Media Literacy

Hasil diagram elemen media literacy menunjukkan ada $84 \%$ siswa dapat mengakses pesan dari sebuah media digital secara baik, 16\% siswa lainnya tidak, karena mereka masih dapat memperoleh dan mengakses konten negatif dari media digital.

\section{Pembahasan}

Siswa kelas X SMAK Santa Maria Malang meskipun dalam situasi pandemi ini telah melaksanakan kegiatan literasi digital yang meliputi tujuh elemen literasi digital yaitu information literacy, digital scholarship, learning skills, ICT literacy, career and identity management, communication and collaboration, dan media literacy. Tujuh elemen literasi digital harus dikuasai oleh siswa, agar mampu bertahan di abad 21 dengan literasi digital (Littlejohn, 2009).

Pada elemen literasi digital pertama yaitu information literacy. 
Siswa mengikuti pembelajaran bahasa Mandarin menggunakan sarana digital seperti teknologi informasi (internet) dalam memecahkan sebuah masalah yaitu mencari, mengevaluasi informasi terlebih dahulu karena mereka menghindari informasi yang salah (hoax) dari YouTube. Siswa setelah mengevaluasi, kemudian menggunakan informasi tersebut secara efektif dalam pembelajaran di situasi pandemi ini (Setyaningsih et al., 2019). Dapat disimpulkan, bahwa elemen information literacy dan teknologi informasi (internet) telah dimanfaatkan secara efektif oleh siswa di masa pandemi ini.

Siswa dalam melaksanakan elemen literasi digital kedua yaitu digital scholarship memanfaatkan secara luas media digital, seperti penyelesaian project akhir bahasa Mandarin, namun ada beberapa siswa tidak sepenuhnya memanfaatkan media digital, ada yang masih memanfaatkan media konfensional dalam menyelesaikan project akhir. Project akhir yang dimaksud adalah pembuatan video YouTube untuk penilaian akhir semester siswa. Digital scholarship dalam kegiatan akademik menjadikan informasi dari media digital sebagai referensi data, misalnya pada praktik penelitian atau penyelesaian tugas kuliah atau sekolah (Stefany, 2017).

Siswa saat melaksanakan pembelajaran daring atau berliterasi digital di rumah telah mengusai elemen literasi digital learning skills meliputi keterampilan berpikir kritis (critical thinking skill, keterampilan komunikasi (communication skill), dan keterampilan kolaborasi (collaboration skill,) kecuali keterampilan creative thinking skill. Mereka masih belum mampu memberikan ide-ide baru kepada orang lain dan menyelesaikan permasalahan mereka dengan cara yang kreatif (problem sloving) dari video bahasa Mandarin. Menyelesaikan permasalahan dengan cara yang kreatif dapat meningkatkan kemampuan berpikir kreatif (Surya, 2017). Solusi dalam permasalahan tersebut adalah membiasakan melakukan literasi fungsional yaitu membaca dan menulis topik yang berkaitan dengan bahasa Mandarin, dengan begitu siswa dapat memberikan suatu hal dari berbagai perspektif (Ibda, 2018)

Elemen literasi digital selanjutnya adalah ICT literacy. ICT literacy menjadi keterampilan dasar dalam pembelajaran jarak jauh. Siswa mempelajari media atau perangkat digital yang telah tersambung internet agar dapat mengikuti pembelajaran daring bahasa Mandarin. Komputer atau LCD proyektor/power point yang telah didesain/dirancang sedemikian rupa agar dapat dimanfaatkan sesuai dengan pemahamannya, apalagi sudah terkoneksi dengan internet sebagai basis pembelajarannya (Setyaningsih et al., 2019). Dalam pelaksanaan elemen ICT literacy ditemukan kendala yaitu, ketika pembelajaran bahasa Mandarin berlangsung siswa kurang memanfaatkan secara optimal media digital dalam proses belajar, disebabkan adanya beberapa aplikasi hiburan di dalam handphone membuat siswa terlalu fokus bermain daripada mengikuti proses pembelajaran bahasa Mandarin. Solusi dari permasalahan tersebut adalah siswa memanfaatkan teknologi secara baik seperti mengurangi kecanduan akan penggunaan handphone dalam proses pembelajaran, guru juga dituntut untuk tegas dan bijak dalam mengatasi permasalahan tersebut dengan begitu dapat membangun keterampilan abad 21 (Zubaidah, 2018).

Siswa dalam berliterasi digital meskipun mengalami kendala seperti lebih banyak menggunakan handphone untuk bermain daripada 
belajar, tetapi dalam pelaksanaan elemen literasi digital career and identity management yaitu selama melaksanakan pembelajaran daring siswa tidak ada kesulitan dalam mengatur waktu belajar karena semua serba online seperti materi pembelajaran, pengumpulan tugas dan lain sebagainya. Siswa mengalami suasana pembelajaran yang tidak terduga karena pandemi ini, tetapi mereka masih bisa mengatasinya. Seseorang dapat bertanggung jawab untuk mengatasi kondisi lingkungan yang berubah dan tak terduga (Mamolar et al., 2018).

Elemen literasi digital selanjutnya adalah communication and collaboration. Siswa mengakses media digital secara aktif dapat mengefisien waktu dan juga mempermudah dalam berkomunikasi, hal tersebut sesuai pendapat dari Stefany (2017) yakni pengguna media digital untuk mengefisienkan waktu, hal ini erat kaitannya dengan media sebagai digital yang memiliki konvergensi. Akan tetapi, ada beberapa siswa ketika pembelajaran bahasa Mandarin mengakses media digital bukan untuk membantu mereka dalam mempelajari bahasa Mandarin, tetapi membuat siswa terlalu fokus bermain daripada mengikuti proses pembelajaran bahasa Mandarin. Solusi dalam permasalahan tersebut dengan critical understanding yaitu menganalisis dan mengevaluasi konten media secara komprehensif, siswa pada waktu jam pembelajaran dapat memfilter atau menelaah penggunaan handphone untuk mencari informasi pembelajaran bukan bermain (Commission \& Unit, 2009).

Elemen literasi digital terakhir adalah media literacy. Berdasarkan hasil lembar checklist, siswa menilai dengan situasi sekarang, penyebaran informasi yang sangat cepat perlu adanya literasi media agar khalayak tidak mudah terperdaya oleh informasi palsu. Hal tersebut sesuai dengan teori dari Rianto (2016) literasi media membuat khalayak tidak mudah terperdaya oleh informasi informasi yang secara sekilas memenuhi dan memuaskan kebutuhan psikologis dan sosialnya.

Berdasarkan pembahasan mengenai elemen literasi digital yang harus dikuasai oleh siswa, ditemukan bahwa siswa telah menguasai enam elemen literasi digital, meskipun ada elemen literasi digital yang masih belum sepenuhnya atau masih rendah dikuasai siswa yakni learning skills dan ada beberapa kendala yang dialami siswa dalam berliterasi digital, seperti siswa kurang memanfaatkan secara optimal media digital dalam proses belajar.

\section{SIMPULAN}

Siswa kelas X SMAK Santa Maria Malang dalam memanfaatkan YouTube berkonten pembelajaran bahasa Mandarin dalam literasi digital di era pandemi ini telah menguasai enam elemen literasi digital meliputi: a) information literacy, b) digital scholarship, c) ICT literacy, d) career and identity management, e) communication and collaboration dan f) media literacy. Adapun elemen literasi digital yang belum sepenuhnya atau masih rendah dikuasai siswa yakni learning skills bagian creative thinking skill, karena siswa belum mampu menyelesaikan permasalahan mereka dengan cara yang kreatif (problem sloving) dari video bahasa Mandarin. Ada beberapa kendala yang dialami siswa dalam berliterasi digital, seperti siswa kurang memanfaatkan secara optimal media digital dalam proses belajar disebabkan adanya beberapa aplikasi hiburan di dalam handphone membuat siswa terlalu fokus bermain daripada mengikuti proses pembelajaran bahasa Mandarin. Siswa dalam berliterasi digital 
meskipun mengalami kendala seperti lebih banyak menggunakan handphone untuk bermain daripada belajar, tetapi dalam pelaksanaan elemen literasi digital career and identity management yaitu selama melaksanakan pembelajaran daring siswa tidak ada kesulitan dalam mengatur waktu belajar karena semua serba online seperti materi pembelajaran, pengumpulan tugas dan lain sebagainya. Siswa mengalami suasana pembelajaran yang tidak terduga karena pandemi ini, tetapi mereka masih bisa mengatasinya.

\section{DAFTAR PUSTAKA}

Commission, F., \& Unit, D. (2009). Study on Assessment Criteria for Media Literacy Levels. http://www.gabinetecomunicacionyedu cacion.com/en/investigacion/studyassessment-criteria-media-literacylevels

Ibda, H. (2018). Penguatan Literasi Baru Pada Guru Madrasah Ibtidaiyah Dalam Menjawab Tantangan Era Revolusi Industri 4.0. In Journal of Research and Thought on Islamic Education (JRTIE) (Vol. 1, Issue 1, pp. 1-21). https://doi.org/10.24260/jrtie.v1i1.106 4

Kharis, Ebner, M., Wijayati, P. H., Hidayat, E., \& Afifah, L. (2020). Microblogging with padlet: Students' new writing experience on A2-B1 common european framework of reference for languages (CEFR). International Journal of Emerging Technologies in Learning, 15(1), 176187.

https://doi.org/10.3991/ijet.v15i01.118 04

Lam, N. H. T., \& Woo, B. K. P. (2020). YouTube as a New Medium for Dementia Education Among Chinese Americans. Community Mental Health Journal, 56(3), 435-439. https://doi.org/10.1007/s10597-01900493-7

Littlejohn, P. R. O. F. A. L. (2009). Thriving in the 21 st century : the report of the LLiDA project ( Learning Literacies for the Digital Age ): Literature Review A JISC funded study
| June 2009. June.

Mamolar, P., Iborra, A., \& Nogueiras, G. (2018). The 'Career Identity and SelfManagement' (IdeCaA) Scale: a Self-Regulatory and Functional Contribution to the Study of Identity. September. https://doi.org/10.13140/RG.2.2.32213. 47842

Pendidikan (Vol. 8, Issue 1, pp. 81-98). https://ejournal.upi.edu/index.php/edul $\mathrm{ib} /$ article/view/11267/PDF

Reyna, J., Hanham, J., \& Meier, P. C. (2018). A framework for digital media literacies for teaching and learning in higher education. E-Learning and Digital Media, 15(4), 176-190. https://doi.org/10.1177/204275301878 4952

Rianto, P. (2016). Media Baru, Visi Khalayak Aktif Dan Urgensi Literasi Media. Jurnal Komunikasi Ikatan Sarjana Komunikasi Indonesia, 1(2), 90.

https://doi.org/10.25008/jkiski.v1i2.54

Riel, J., \& Christian, S. (2016). Charting Digital Literacy: A Framework for Information Technology and Digital Skills Education in the Community College. SSRN Electronic Journal, March 2018. https://doi.org/10.2139/ssrn.2781161

Schwab. (2016). The Fourth Industrial Revolution: what it means, how to respond.

https://www.weforum.org/agenda/201 6/01/the-fourth-industrial-revolution- 
what-it-means-and-how-to-respond/

Setyaningsih, R., Abdullah, A., Prihantoro, E., \& Hustinawaty, H. (2019). Model Penguatan Literasi Digital Melalui Pemanfaatan E-Learning. Jurnal ASPIKOM, 3(6), 1200. https://doi.org/10.24329/aspikom.v3i6. 333

Stefany, S. (2017). Literasi Digital Dan Pembukaan Diri: Studi Korelasi Penggunaan Media Sosial Pada Pelajar Remaja di Kota Medan. Sosioglobal: Jurnal Pemikiran Dan Penelitian Sosiologi, 2(1), 10-31. https://doi.org/10.24198/jsg.v2i1.1526 8

Surya, E. (2017). International Journal of Sciences: Differences in the Abilities of Creative Thinking and Problem Solving of Students in Mathematics by Using Cooperative Learning and Learning of Problem Solving. International Journal of Sciences: Basic and Applied Research (IJSBAR), 34(1), 286-299.

YouTube Creator Academy. (2018). $\mathrm{https}$ ://creatoracademy.youtube.com/p age /lesson/educhannelstart?hl=id\#strategies-zippylink-3

Zubaidah, S. (2018). Mengenal 4C: Learning and Innovation Skills untuk Menghadapi Era Revolusi Industri 4.0. 2nd Science Education National Conference, April, 1-18. https://www.researchgate.net/publicati on/332469989_Mengenal_4c_Learnin g_And_Innovation_Skills_Untuk_Men ghadapi_Era_Revolusi_Industri_ $\overline{40} \_1$ 